SHORT COMMUNICATION

Sokoto Journal of Veterinary Sciences

(P-ISSN 1595-093X: E-ISSN 2315-6201)

http://dx.doi.org/10.4314/sokjvs.v17i3.8

Esonu et al./Sokoto Journal of Veterinary Sciences, 17(3): 48 - 51.

\title{
Retrospective study on the prevalence of Babesia species in traumatic cases of dogs presented to Veterinary Teaching Hospital, ABU Zaria, Nigeria from 2008 - 2018
}

\author{
DO Esonu ${ }^{1 *}$, RG Otolorin ${ }^{2}, \mathrm{FM}$ Per $^{3} \& \mathrm{CM}$ Esonu ${ }^{4}$ \\ 1. Department of Veterinary Public Health and Preventive Medicine, Faculty of Veterinary Medicine, \\ Ahmadu Bello University, Zaria, Kaduna State, Nigeria \\ 2. Department of Veterinary Public Health and Preventive Medicine, Faculty of Veterinary \\ Medicine, University of Jos, Jos Plateau Stat, e Nigeria \\ 3. Department of Veterinary Public Health and Preventive Medicine, Faculty of Veterinary \\ Medicine, Federal University of Agriculture, Makurd, i Benue State, Nigeria. \\ 4. Department of Veterinary Microbiology, Faculty of Veterinary Medicine, Ahmadu Bello \\ University, Zaria, Kaduna State, Nigeria
}

\begin{abstract}
Copyright: (c) 2019 Esonu et al. This is an open-access article published under the terms of the Creative Commons Attribution License which permits unrestricted use, distribution and reproduction in any medium, provided the original author and source are credited.
\end{abstract}

*Correspondence: Tel.: +234 8061604710; E-mail: esonu25@gmail.com

Publication History: Received: 04-07- 2019 Accepted: 30-08-2019 factor to Babesia infection in dogs.
Babesia infection is increasing in prevalence and is now a major problem in dogs. During this study, a total of 358 case-files recorded between 2008-2018 (11 years) were retrieved from the Small Animal Clinic of the Veterinary Teaching Hospital, Ahmadu Bello University, Zaria, with the chief complaint of trauma of different forms. These dogs were registered in the clinic and were on routine veterinary medical care before presentation for trauma. For each case, the Protozoology laboratory results were matched with the records from the Small Animal Clinic reception to determine whether there was Babesia species in the blood, precipitated by the trauma. Statistical analysis showed that $3.1 \%$ of the dogs presented with traumatic injuries within the study period were found to be positive for Babesia species. Male dogs (3.6\%) with traumatic injuries were more prone to the infection than female dogs $(2.3 \%)$, whereas the prevalence of Babesia species was higher in younger dogs (17.4\%) with same condition than older age groups $(2.1 \%)$. Crossbreds $(7.5 \%)$ with traumatic injuries were more prone to the infection than the exotic $(4.5 \%)$ and local breed $(0.9 \%)$. However, none of them were completely resistant. Statistical analysis of the data obtained showed that there was a significant association between the presence of Babesia species and the age and breed of dogs with traumatic injuries that were presented to the clinic. This study has shown that traumatic injuries could be a predisposing

Keywords: Babesia, Blood, Case-files, Dogs, Prevalence, Trauma, Zaria

\section{Introduction}

Babesia canis is a tick-transmitted hemoprotozoan parasite that induces anaemia, fever, jaundice, ahemoglobinuria and sometimes fatal symptoms in dogs. $B$. canis is classified into three subspecies: $B$. canis rossi, $B$. canis vogeli and $B$. canis canis. The arthropod vectors of $B$. canis rossi, B. canis vogeli and $B$. canis canis are Haemaphysalis leachi, Rhipicephalus sanguineus and Dermacentor reticulatus, respectively (Oyamada et al., 2005). 
There are more than 100 known Babesia species. Babesiosis is one of the most common infectious diseases of mammals worldwide and it has gained increasing interest as its zoonotic potential has become increasingly recognized (Homer et al., 2000). The increasing number of canine Babesia species, geographical distribution, varying tick vectors and modes of transmission often result in diverse of pathogenic and clinical presentations (Ayoob et al., 2010).

The clinical and pathological presentation of canine babesiosis varies and is also dependent on the species/subspecies responsible for the infection; however, the classical presentations often include: thrombocytopaenia, febrile syndrome (fever, anorexia, depression, dehydration) and haemolytic syndrome (anaemia, bilirubinuria, haemolysis) in acute cases while the chronic form corresponds to prolonged convalescence characterized by depression (Solano-Gallego et al., 2008).

Like other mammalian hosts, dogs are susceptible to intestinal parasitic helminthes and protozoa, including species of epidemiological significance that may be a source of severe disease for humans (Bajer et al., 2010). Dogs may also be infected with pathogenic haemoparasites including Babesia species (Nalubamba et al., 2011). Canine babesiosis has been described as an emerging veterinary problem worldwide (Irwin, 2009).

Transmission of Babesia parasite to the canine host is by the bite of specific ixodid tick vectors. Thus, the specie of Babesia prevalent in a particular area is influenced by the presence of the specific tick vector in that geographical area (Matjila et al., 2004). Infection in dog may also occur by direct transmission via blood transfer from dog bites, blood transfusion or transplacental transmission (Uilenberg, 2006).

Babesia infections are traditionally diagnosed based on the detection of the parasites in thin blood smears stained with Giemsa, Romanowsky and field stains under a microscope. The blood smears prepared from capillary blood and buffy coat readily reveals the parasites since the parasitized erythrocytes tend to sludge in the capillaries and also preferentially parasitize the reticulocytes over the mature red blood cell (Bohm et al., 2005).

Trauma encompasses physical or psychological injury to a human or animal (WebMD, 2008) Physical injury can be caused by nonpenetrating (blunt) or penetrating trauma. Blunt trauma includes vehicular trauma, crush/compression or acceleration/deceleration injury. Traumatic injury can result in acute death due to overwhelming primary damage, initial survival and subsequent death due to complications (delayed haemorrhage, multiorgan dysfunction, infection or sepsis) or patient survival to discharge (Sauaia, 1995).

The systemic response to severe injury involves interactions across the haemostatic, inflammatory, endocrine and neurological systems, aggravating initial damage caused by hypoperfusion (shock) and reperfusion. Endothelium activated by exposure to inflammatory cytokines becomes more porous, allowing mediators of tissue damage to gain access to the intercellular space. The systemic responses to major trauma are also associated with lowered ability to fight infection, leading to sepsis and further activation of the destructive inflammatory response (Lord et al., 2014). Severe injury is associated with the Systemic Inflammatory Response Syndrome (SIRS) (Zhang et al., 2010). The inflammatory response also includes rapid activation of the complement system - initial activation is followed by consumption and a subsequent imbalance in the components of the complement cascade, which is one of many factors that reduces the ability of the body to defend against microorganisms (Burk et al., 2012).

The aim of the study was to determine the prevalence of Babesia species in traumatic cases of dogs presented to the Small Animal Clinic of the Veterinary Teaching Hospital, ABU Zaria. This may add more knowledge to this disease in Zaria, which in turn may help to control the disease, through avoiding as much as possible the exposure of dogs to different forms of trauma which depresses their immunity, predisposing them to this disease.

\section{Materials and Methods \\ Study design}

Total of 358 case-files recorded between 2008-2018 (11 years) were retrieved from the Small Animal Clinic of the Veterinary Teaching Hospital, Ahmadu Bello University, Zaria. All had the chief complaint of trauma of different forms. History revealed that the dogs were registered and were receiving routine veterinary medical care such as tick bath, deworming, vaccination etc. before presentation for trauma. History also revealed that blood samples were collected from the cephalic vein of all the dogs presented and sent to the Protozoology laboratory for haemoparasite screening. The blood samples containing Ethylene Di-amine Tetra-acetic Acid (EDTA) were examined using Giemsa stained thin blood smears to detect Babesia species pyriform and or round shape piroplasms in red blood cells.

For each case-file, the Protozoology laboratory results were matched with the records from the small animal clinic reception to determine whether there was Babesia species in the blood, possibly precipitated by the trauma. 
Data analysis

Data retrieved from the case-files were analyzed with Statistical Package for Social Science (SPSS) version 20.0. Chi-square was used to determine association between Babesia species and factors such as age, sex and breed. Odds ratio (OR) and $95 \%$ confidence interval were used on dichotomous variables to test the strength of association. $P$ values $\leq 0.05$ were considered significant.

\section{Results and Discussion}

The overall prevalence of Babesia species in dogs with traumatic injuries was 3.1\% (Table 1). Higher prevalence of Babesia species was observed in dogs less than one year of age (17.4\%) with traumatic injuries than dogs of at least one year of age $(2.1 \%)$ with traumatic injuries. Statistical analysis of the data revealed that there was significant association $(p=0.00)$ between the presence of Babesia species and age of dogs with traumatic injuries that were presented to the clinic. Information from the analyzed data also revealed that male dogs (3.6\%) with traumatic injuries could be more prone to Babesia infection than female dogs (2.3\%) with the same condition, though there was no significant association $(p=0.491)$ between the presence of Babesia species and sex of dogs with traumatic injuries. The highest percentages of Babesia species positive cases were found in crossbreds (7.5\%), followed by exotic breeds (4.5\%), whereas lowest percentages were found in local breeds (0.9\%). Statistical analysis of the data showed that there was significant association $(p=0.004)$ between the presence of Babesia species and breed of dogs with traumatic injuries that were presented to the clinic within the period.

The results of the present study suggest that dogs < 1 year of age were more likely to be infected with
Babesia species than the dogs of other ages with traumatic injuries. This may be due to an increased susceptibility to infection or less immunity due to traumatic injury. On the other hand, the older dogs were less prone to Babesia infection this may be due to non-specific or innate factors possessed by the hosts which act as natural protective element (Levy et al., 1982). The study suggests that male dogs could be more prone to this disease than the females, which indicates bite wounds or blood transmission during fighting contact in male dogs, thus possible routes of transmission for Babesia parasite. The study also showed that the most susceptible breed of dogs in Zaria were crossbred dogs, followed by the exotic and the local breed. This may be due to the modification of genetic traits in the course of breeding which may lead to changes in innate immunity, increasing susceptibility to the infection.

Traumatic injuries may result in loss of continuity, loss of function, pain and haemorrhage. The most frequent causes of trauma in small animals are automobile accidents, bites from other animals, broken glass and other sharp objects. The location, nature and extent of the lesions vary from the smallest abrasion to gross lacerations that are badly contaminated and accompanied by complicating internal injuries like splenic ruptures. Other organs of the immune system which may be traumatized in cases of Road Traffic Accident (RTA) include bone marrow, the thymus, various lymph nodes and aggregates of lymph tissue spread throughout the body. The possibility of trauma predisposing dogs to heavy tick infestation, probably by been immobilized as a result of the trauma exist, thus increased tick infestation in dog increases the chances of Babesia infection as ticks serve as vectors.

Table 1: Prevalence of Babesia species in traumatic cases of dogs presented at the Veterinary Teaching Hospital, ABU Zaria from $2008-2018$

\begin{tabular}{lllllll}
\hline Factors & & $\begin{array}{l}\text { Number } \\
\text { examined }\end{array}$ & $\begin{array}{l}\text { Number } \\
\text { positive }\end{array}$ & $\begin{array}{l}\text { Specific } \\
\text { rate (\%) }\end{array}$ & $\begin{array}{l}\text { Odds ratio } \\
\text { (OR) }\end{array}$ & $\begin{array}{l}\text { 95\% confidence } \\
\text { interval on OR }\end{array}$ \\
\hline Age* & $<1$ year & 23 & 4 & 17.4 & 9.87 & $2.66-36.66$ \\
\multirow{2}{*}{ Sex** } & $\geq 1$ year(ref) & 335 & 7 & 2.1 & 1.0 & - \\
& Male & 225 & 8 & 3.6 & 1.60 & $0.416-6.129$ \\
Breed*** & Female(ref) & 133 & 3 & 2.3 & 1.0 & - \\
& Local breed & 229 & 2 & 0.9 & - & - \\
& Crossbred & 107 & 8 & 7.5 & - & - \\
& Exotic breed & 22 & 1 & 4.5 & - & - \\
& Total & 358 & 11 & 3.1 & & \\
\end{tabular}

\footnotetext{
Ref $=$ reference category

$* X=16.921, p=0.000$

$* * X=0.474, p=0.491$

$* * * X=10.848, \mathrm{p}=0.004$
} 


\section{Acknowledgements}

We sincerely appreciate the efforts of laboratory staff of Departments of Parasitology and Entomology and staff of the small animal clinic section of the Veterinary Teaching Hospital, Faculty of Veterinary Medicine, Ahmadu Bello University, Zaria, in seeing to the completion of this research work.

\section{References}

Ayoob AL, Hackner SG \& Prittie J (2010). Clinical management of canine babesiosis. Journal of Veterinary Emergence and Critical Care, 20(1): 77-89.

Bajer A, Bednarska M \& Rodo A (2010). Risk factors and control of intestinal parasite infections in sled dogs in Poland. Veterinary Parasitology, 175(3-4): 343-350.

Bohm M, Leisewitz AL, Thompson PN \& Schoeman JP (2005). Capillary and venous Babesia canis rossi parasitaemia and their association with outcome of infection and circulatory compromise. Veterinary Parasitology, 141(1-2): 18-29.

Burk AM, Martin M, Flierl MA, Rittirsch D, Helm M \& Lampl L (2012). Early complementopathy after multiple injuries in humans. Shock (Augusta, Ga.), 37(4): 348-54.

Homer MJ, Aguilar-Delfin I, Telford SR, Krause PJ \& Persing DH (2000). Babesiosis. Clinical Microbiology Reviews, 13(3): 451-469.

Irwin PJ (2009). Canine babesiosis: From molecular taxonomy to control. Parasites \& Vectors, 2(Suppl 1): S4.

Levy MG, Clabaugh G \& Ristic M (1982). Age resistance in bovine babesiosis: Role of blood factors in resistance to Babesia bovis. Infection Immunity, 37(3): 11271131.
Lord JM, Midwinter MJ, Chen Y, Belli A, Brohi K, Kovacs EJ, Koenderman L, Kubes P \& Lilford RJ (2014). The systemic immune response to trauma: an overview of pathophysiology and treatment. The Lancet, 384(9952): 1455-1465.

Matjila PT, Penzhorn BL, Bekker CPJ, Nijhof AM \& Jongejan $F$ (2004). Confirmation of occurrence of Babesia canis vogeli in domestic dogs in South Africa. Veterinary. Parasitology, 122(2): 119-125.

Nalubamba KS, Hankanga C, Mudenda BN \& Masuku M (2011). The epidemiology of canine babesiosis infections in Zambia. Preventive Veterinary Medicine, 99(2-4): 240-244.

Oyamada $M$, Davoust B, Boni $M$, Dereure J, Bucheton B, Hammad A, Itamoto K, Okuda, $M$ \& Inokuma H (2005). Clinical Diagnostic Laboratory Immunology. 12: 1343-134.

Sauaia A, Moore FA \& Moore EE (1995). Epidemiology of trauma deaths: a reassessment. Trauma, 38(2): 185-193.

Solano-Gallego L, Trotta M, Carli E, Carcy B, Caldin $M \quad \& \quad$ Furlanello $T$ (2008). Clinicopathological findings and DNA detection by means of PCR-RFLP in blood from Italian dogs suspected of tick-borne disease. Veterinary Parasitology, 157(3-4): 211-221.

Uilenberg (2006). Babesia--A historical overview. Veterinary Parasitology, 138(1-2): 3-10.

Webster's New World Medical Dictionary (2008), third edition. USA: Wiley Publishing Inc.

Zhang $Q$, Raoof $M$, Chen $Y$, Sumi $Y$, Sursal T \& Junger W (2010). Circulating mitochondrial DAMPs cause inflammatory responses to injury. Nature, 464 (7285): 104-107. 